\title{
Familial eruptive syringoma
}

\author{
Mahizer Yaldiz ${ }^{\text {* }}$, MD, Cihan Cosansu', MD, Mustafa T Erdem ${ }^{1}$, MD, Bahar S Dikicier ${ }^{1}, M D$, \\ Zeynep Kahyaoğlu², MD
}

Departments of ${ }^{1}$ Dermatology and ${ }^{2}$ Pathology, Sakarya University Training and Research Hospital, Sakarya, Turkey

*Corresponding author: drmahizer@gmail.com

Hong Kong Med J 2018:24:200-2

DOI: 10.12809/hkmj144415

\section{Case presentations}

\section{Case 1}

A 20-year-old woman presented with a 4-year history of progressive papular rash in January 2010. The rash had started on her neck. The patient was otherwise healthy and had no other skin complaints and no family history of any skin diseases. She reported that her brother had similar lesions. Physical examination of the patient revealed widely distributed fleshcoloured red-brown smooth papules of 1 to $5 \mathrm{~mm}$ on the neck and supraclavicular region (Fig 1a). Skin biopsy and subsequent histopathological examination revealed dermis that was filled with multiple ducts embedded in a dense collagenous stroma. The ducts were lined by an inner layer of flattened epithelial cells that had a comma-like appearance. Syringoma was diagnosed (Fig 1b).

\section{Case 2}

A 25-year-old man, the brother of the patient in case 1 , presented with a 10-year history of progressive papular rash in January 2010. The rash had started on the back and upper chest. The patient was otherwise healthy, with no other skin complaints and a negative family history for any skin diseases, other than his sister. Physical examination revealed widely distributed, flesh-coloured brown papules of 1 to 5 $\mathrm{mm}$ on the anterior and posterior aspect of the trunk (Fig 2a). Histopathological examination revealed that the dermis was filled with multiple ducts embedded in a collagenous stroma and the ducts were lined by an inner layer of flattened epithelial cells that had a comma-like appearance (Fig 2b).

On the basis of the clinical and histopathological findings, both cases were diagnosed as familial eruptive syringoma. Because this condition is benign, treatment modalities were discussed with both patients, with particular reference to 'poor' cosmetic outcome and the risk of recurrence. Both patients opted for no intervention. They were advised to avoid hot environments as much as possible and were given an open appointment at the dermatology department.

\section{Discussion}

The word syringoma is derived from the Greek

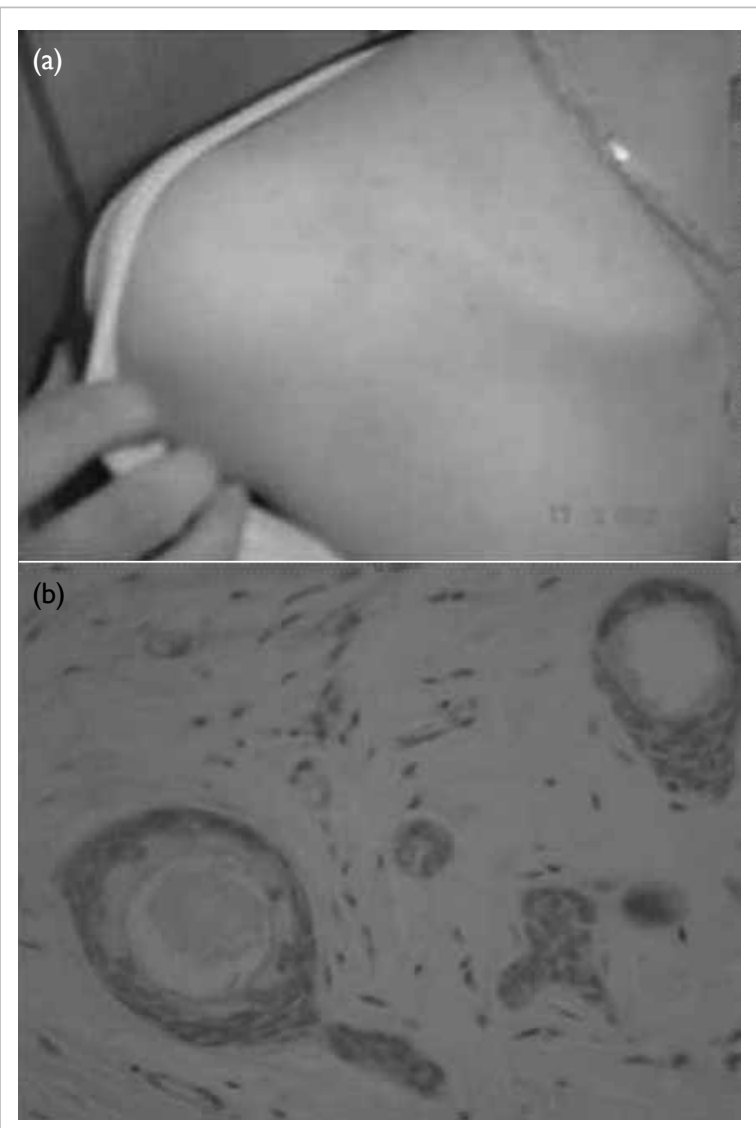

FIG I. (a) Widely distributed flesh-coloured papules on the neck and supraclavicular region. (b) Photomicrograph showing dermis that is filled with multiple ducts embedded in a dense collagenous stroma; the ducts are lined by an inner layer of flattened epithelial cells that have a comma-like appearance (H\&E; original magnification, $\times$ 200)

word syrinx meaning pipe or tube. ${ }^{1}$ Syringoma is a benign adnexal neoplasm that is formed by welldifferentiated ductal elements. Lesions have largely cosmetic significance and affect approximately $1 \%$ of the population. ${ }^{1,2}$ Syringomas usually first appear at puberty and are generally asymptomatic; additional lesions can develop later. Neither of our patients had any symptoms, although rarely individuals may experience pruritus, especially during perspiration. ${ }^{2}$ Clinically, syringomas manifest as small skin- 


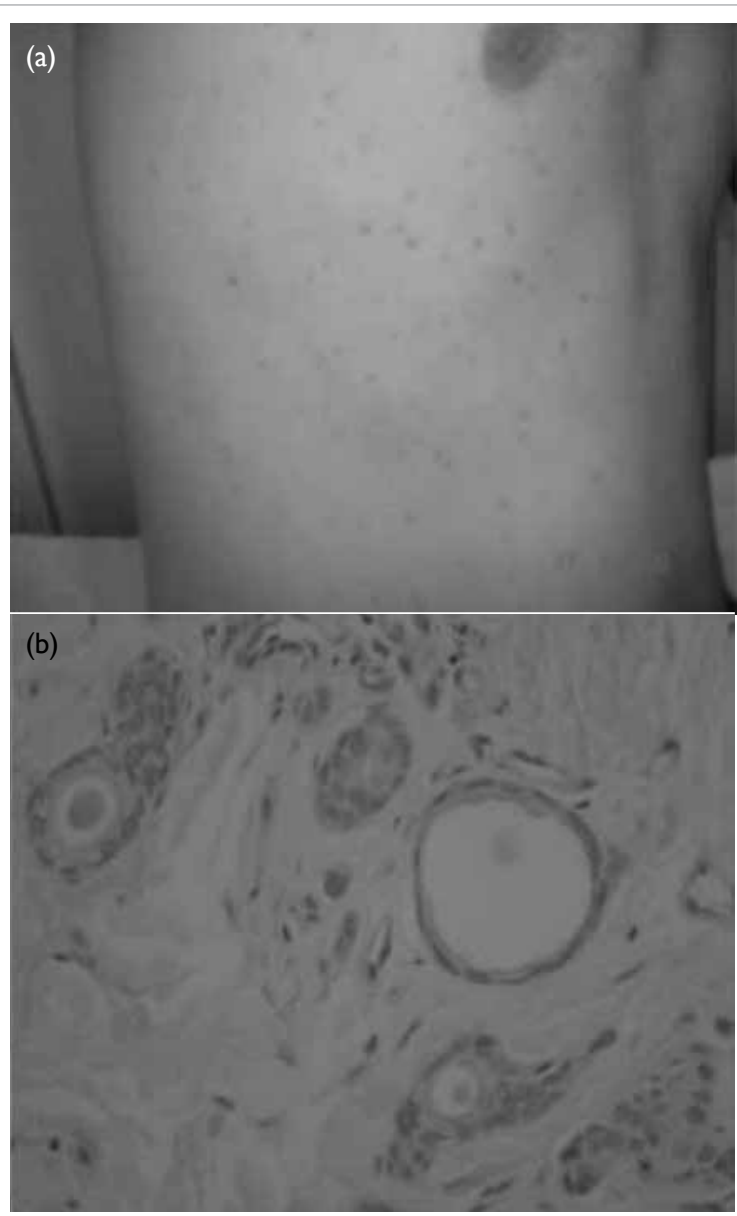

FIG 2. (a) Widely distributed flesh-coloured papules on the anterior and posterior aspect of the trunk. (b) Photomicrograph showing dermis filled with multiple ducts embedded in a collagenous stroma; the ducts are lined by an inner layer of flattened epithelial cells that have a comma-like appearance (H\&E; original magnification, $\times 200)$ coloured or slightly pigmented papules. Although the peri-orbital region is the most commonly involved site, the neck, supraclavicular region, and the anterior and posterior aspect of the trunk may also be affected, especially in the eruptive form, as seen in our patients.

Syringomas are classified into four clinical types: localised, familial, generalised, and Down's syndrome-associated. The generalised type encompasses multiple and eruptive syringomas. ${ }^{3}$ Eruptive syringoma is a rare variant that was first described by Jacquet and Darier in 1887. ${ }^{4}$ The lesions in eruptive syringoma occur in large numbers and in successive crops at puberty or during childhood. They can occur on the anterior chest, neck, upper abdomen, axillae, and the periumbilical region. They are almost always multiple and most frequently occur on the eyelids and upper cheeks. Eruptive syringomas are described more frequently in patients with Down's syndrome and Ehlers-Danlos syndrome. $^{5}$ In our patients, there was no such association.

Rarely, a patient with eruptive syringomas may have a family history of similar lesions. Familial eruptive syringoma is a rare condition that is likely to be inherited in an autosomal dominant manner. To the best of our knowledge, only a few cases of familial eruptive syringoma have been reported worldwide. Our two patients represent typical cases of familial eruptive syringomas. Reed ${ }^{6}$ described a family in which seven females and one male in four generations were affected. Patrone and Patrizi ${ }^{7}$ reported on a family (mother, daughter, and son) with dominantly inherited eruptive syringoma. Marzano et $\mathrm{al}^{2}$ reported on a family with multiple syringomas that affected members of three successive generations, and described in detail a 36-year-old woman and her 17-year-old son. Lau and Haber ${ }^{8}$ reported two cases of eruptive syringoma within a family, in which the lesions were widely distributed over the trunk of a healthy 16-year-old female and her 19-year-old brother.

Skin biopsies of the lesions are the best means of diagnosing syringoma, because the microscopic appearance is characteristic of the condition. Histologically, syringomas are characterised by dilated cystic spaces lined by two layers of cuboidal cells and epithelial strands of similar cells. Some of the cysts have what resemble small tails that look like commas or tadpoles, and in a group they produce a distinctive paisley-like pattern. There is also a dense fibrous stroma.

The differential diagnosis of eruptive syringomas must be made while considering other papular dermatosis that frequently appear during childhood-for example, plane warts, acne vulgaris, lichen planus, granuloma annulare, papular sarcoidosis, milia, sebaceous hyperplasia, eruptive xanthoma, urticaria pigmentosa, Darier's disease, pseudoxanthoma elasticum, or hidrocystoma. Histological differential diagnoses include sclerosing (morphea-like) basal-cell carcinoma and desmoplastic trichoepithelioma. Importantly, syringoma must be distinguished from microcystic adnexal carcinoma, which has similar histological features but tends to infiltrate the deep dermis and subcutaneous tissue.

Despite the availability of numerous treatment options, their efficacy is limited because the tumours are located in the dermis and the risk of recurrence is high. Treatment is difficult, although many lesions respond to very light electrodessication or removal by shaving. Carbon dioxide laser treatment by the pinhole method and fractional thermolysis have been reported to be effective in removal. For larger lesions, surgical removal may be considered. Other 
treatment modalities that have been used include cryosurgery, chemical peeling, dermabrasion, and oral and topical retinoids. ${ }^{9}$ Our two patients initially requested treatment but then opted for no intervention.

\section{References}

1. Haubrich W. Medical Meaning: A Glossary of Word Origins. US: American College of Physicians; 2003: 233.

2. Marzano AV, Fiorani R, Girgenti V, Crosti C, Alessi E. Familial syringoma: report of two cases with a published work review and the unique association with steatocystoma multiplex. J Dermatol 2009;36:154-8.

3. Friedman SJ, Butler DF. Syringoma presenting as milia. J Am Acad Dermatol 1987;16:310-4.
4. Jacquet L, Darier J. Hiydradénomes éruptifs, épithéliomes adénoides des glandes sudoripares ou adénomes sudoripares. Ann Dermatol Syph 1887;8:317-23.

5. Hertl-Yazdi M, Niedermeier A, Hörster S, Krause W. Penile syringoma in a 14-year-old boy. Eur J Dermatol 2006;16:314-5.

6. Reed WB. Genetic aspects in dermatology [in German]. Hautarzt 1970;21:8-16.

7. Patrone P, Patrizi A. Familial eruptive syringoma [in Italian]. G Ital Dermatol Venereol 1988;123:363-5.

8. Lau J, Haber RM. Familial eruptive syringomas: case report and review of the literature. J Cutan Med Surg 2013;17:848.

9. Garrido-Ruiz MC, Enguita AB, Navas R, Polo I, Rodríguez Peralto JL. Eruptive syringoma developed over a waxing skin area. Am J Dermatopathol 2008;30:377-80. 